author concentrates on the production of mosaics and chimaeras to analyse these problems. A special account is devoted to the very topical area of determination mutants where the homoeotic mutants are investigated along with the problems of sex determination; this is particularly useful as many of the molecular studies on these systems demand an understanding of large amounts of background genetics which are rarely documented in such a complete form that students can see how progress has been possible and begin to tackle reading the research papers. The final section on future developments concentrates on cellular

\section{Nervous connections}

\section{Julian Lewis}

\section{Development of Nerve Cells and Their} Connections.

By W.G. Hopkins and M.C. Brown. Cambridge University Press: 1984.

Pp. 137. Hbk £16, \$29.95; pbk £6.95,

$\$ 13.95$.

Principles of Neural Development.

By Dale Purves and Jeff W. Lichtman. Sinauer/Blackwell Scientific: 1985.

Pp.433. \$32.50, £29.50.

From Neuron to Brain, 2nd Edn. By Stephen W. Kuffler, John G. Nicholls and A. Robert Martin.

Sinauer/Blackwell Scientific: 1984.

Pp.651. Hbk \$30; pbk £14.80.

THE development of the nervous system is not yet one of those subjects where a set of fundamental principles emerges neatly from a series of crucial experiments. Perhaps it will be one day: therein lies the challenge. To optimists, the published literature seems like the jumbled pieces of a giant jigsaw puzzle: find the right arrangement, and a beautifully coherent picture will emerge. Others, with less faith in universal principles, may perceive only a rambling mass of natural history anecdotes, fascinating to relate, but with no more logical unity than the Arabian Nights entertainments.

In Development of Nerve Cells and Their Connections, Hopkins and Brown adopt a sober and businesslike approach: their short, well-referenced and very reasonably-priced book offers a terse, dispassionate review of what is known about neural development, beginning with the genesis of neurones in the embryo and ending with plasticity and regeneration in the adult. They do not attempt to dramatize the data, and the reader is often left to supply his own emphases. For this reason, and because the presentation is rather condensed and bare of practical details or pictures of the numerous experimental systems discussed, the book, and especially its first half, may be hard going for newcomers to the subject. I found the second half, dealing with the modification systems, a personal view of which areas of research are likely to be fruitful, and the book ends with an analysis of problems still to be solved.

In this book Sang has succeeded in bringing together the classical genetic approach of using mutations to study development with the more recent molecular techniques. I'm sure it will be of great use to students of both genetics and developmental biology.

Mary Bownes is a Lecturer in the Department of Molecular Biology at the University of Edinburgh.

of neural connections, the more valuable. As one might expect from these authors, it includes a particularly lucid discussion of synapse elimination and of nerve sprouting. And it is the only one of the books under review that has the courage to tackle head-on, in a few useful and wellorganized pages, the problem of learning and memory; the other two venture only a sideways glance at this central enigma.

Purves and Lichtman's larger and more ambitious book, Principles of Neural Development, is a masterpiece: comprehensive but not stodgy, clear, accurate, elegantly written, beautifully and copiously illustrated. Even if you don't like words, you will be seduced by the pictures. While it does not offer any revolutionary new synthesis, the book succeeds, better than any previous text on the subject, in the very difficult task of weaving the inchoate mass of data on neural development into a single coherent narrative. Despite the 47 pages of references, and a scholarly care in assigning credit and priorities, Purves and Lichtman avoid the dismal blight that often afflicts Annual Reviews, where so many experiments are squeezed into so small a space that no life is left in them. Key experiments are made vivid and concrete by means of figures displaying the methods, materials and observations, reproduced as far as possible from the original papers.

The historical antecedents of modern work are particularly well portrayed. I enjoyed especially the short (one page) biographies of scientists, past and present, who have played major parts in the story. These sketches provide more than the usual bland catalogue of dates and discoveries, managing, in a few paragraphs, not only to explain how and why the scientific achievements were important, but also to bring the characters to life. Purves and Lichtman also have an excellent way with unresolved scientific conflicts: they set out the arguments fairly and squarely, and then tactfully and undogmatically offer their own judgement. As from all the best books, one learns about a great deal more than the title promises, from the principles of Nomarski interference contrast to the discomforts of wearing a reversing pseudophone.
From Neuron to Brain, by Kuffler, Nicholls and Martin, is the second edition of a classic. The first edition was for me and many others a memorable and engrossing introduction to the cellular basis of neurophysiology. It succeeded in large measure by sticking to the excellent principle that it is better - and more fun to learn ten things well than a hundred things superficially. The authors focused on topics that they knew intimately, and conveyed their fascination with them.

The new edition retains the structure and much of the text of the old, but is enlarged by about $30 \%$. It opens, as before, with a discussion of how neurones represent information about the visual world, updated where appropriate but as good as ever. Spurred on and sustained by the sense that the workings of neurones are the key to the higher functions of the brain, the reader is then taken through the more arduous analysis of the electrical properties of neurones and of synaptic transmission.

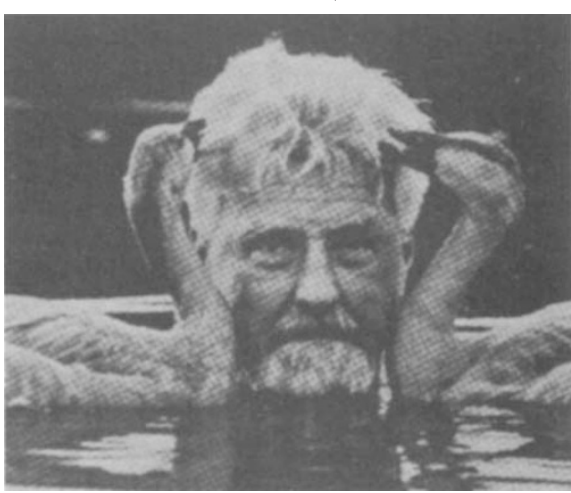

Konrad Lorenz with his geese. The picture is reproduced from one of the short biographies in Principles of Neural Development.

The revision here has been more drastic, making the account more rigorous, more complete and less readable for beginners. New topics such as patch clamp recording of currents through single channels are covered clearly and concisely, though sometimes without as much adjustment of the balance of emphasis as they deserve. One does not get the sense that any of the new techniques and discoveries of the past eight years have yielded any radical changes in our perception of neurones or the nervous system, or made any significant part of the material in the first edition obsolete. Is it really true, as stated in the "Concluding Remarks", that "we still do not understand the basic mechanisms that underlie changes in membrane permeability and active transport"?

Subsequent chapters include, together with the old material, many good new things, from sensitization in Aplysia to the role of the basal lamina in synapse formation, and a whole new chapter on the control of movement. This is still an outstanding book.

Julian Lewis is a Lecturer in the Department of Anatomy at King's College, University of London. 